\title{
O BIBLIOTECÁRIO MEDIADOR E OS DESAFIOS PARA A COMPETÊNCIA EM INFORMAÇÃO DIANTE DA COVID-19: o caso de uma biblioteca universitária especializada em saúde
}

\section{THE MEDIATING LIBRARY AND THE CHALLENGES FOR COMPETENCE IN}

INFORMATION BEFORE COVID-19: the case of a university library specializing in health

Karina Barbosa dos Santos ${ }^{1}$

\begin{abstract}
RESUMO
Este artigo tem por objetivo descrever o relato de experiência profissional do primeiro Programa de Capacitação que deu origem ao curso online "Aprendendo sobre normas da ABNT" oferecido por uma biblioteca universitária (BU) especializada em ciências da saúde, Programa implantado a partir do produto final de um projeto de pesquisa de mestrado. Aborda as ações que vem sendo trabalhadas pela biblioteca durante o período pandêmico, com o uso intensivo das redes sociais, e aprimoramento do profissional na competência em mídia. Mostra os desafios enfrentados pelo bibliotecário através dos trabalhos home office e como pensar em práticas para dar continuidade ao desenvolvimento da competência em informação dos usuários remotamente. A metodologia caracteriza-se como um estudo empírico e descritivo, de abordagem qualiquantitativa, que utiliza como instrumento, o questionário pesquisa de satisfação, e também faz uso da revisão bibliográfica para a fundamentação teórica. Os resultados obtidos apontam que entre os participantes $62,5 \%$ sentiram-se satisfeitos com o curso. Em relação à duração da capacitação, 50\% marcaram "excelente" para a carga horária. Quanto ao objetivo proposto pelo curso, $98,5 \%$ alegaram que o conteúdo estava de acordo com o estimado na divulgação. Diante das considerações finais, recomenda-se que atividades remotas sejam realizadas a fim de promover a competência em informação aos usuários das bibliotecas universitárias frente as práticas de isolamento social. A biblioteca em estudo pretende promover outros cursos, principalmente os voltados para o uso de ferramentas das bases de dados em saúde para uma melhor disseminação no uso e gestão da informação científico-técnica em saúde. Os estudos de Morigi e Souto (2005), Kern (2020), Santos e Paiva (2020) e Santos (2020) foram fundamentais para esta pesquisa, pois serviram como embasamento teórico para o desenvolvimento deste artigo.
\end{abstract}

Palavras-chave: bibliotecas universitárias; ciência da saúde; mídias sociais; competência em informação; COVID-19.

\section{ABSTRACT}

1 Graduação em Biblioteconomia e documentação pela Universidade Federal Fluminense - UFF (2010). Pós-graduação em Gestão estratégica da Tecnologia da Informação pela Universidade Estácio de Sá (2014). Mestra em Biblioteconomia pela Universidade Federal do estado do Rio de Janeiro - UNIRIO (2020). Atualmente exerço o cargo de bibliotecária no Instituto Federal de Educação, Ciência e Tecnologia do Rio de Janeiro, campus Realengo, como coordenadora da biblioteca desde o ano de 2017 até o momento.

R. Bibliomar, São Luís, v. 20, n. 2, p., jul./dez. 2021. 
This article aims to describe the professional experience report of the first Training Program that gave rise to the online course "Learning about ABNT standards" offered by a university library (BU) specialized in health sciences, Program implemented based on the final product of a master's research project. It addresses the actions that have been worked on by the library during the pandemic period, with the intensive use of social networks, and professional improvement in media competence. It shows the challenges faced by the librarian through home office work and how to think about practices to continue the development of users' information competence remotely. The methodology is characterized as an empirical and descriptive study, with a qualitative and quantitative approach, the satisfaction survey questionnaire was used as an instrument. A literature review was also carried out as a theoretical basis for the present study. The results obtained show that among the participants $62.5 \%$ felt satisfied with the course. Regarding the duration of the training, $50 \%$ scored "excellent" for the workload. As for the objective proposed by the course, $98.5 \%$ claimed that the content was in accordance with the estimated disclosure. In view of the final considerations, it is recommended that remote activities be carried out in order to promote competence in information to users of university libraries in the face of social isolation practices. The library under study intends to promote other courses, mainly those focused on the use of health database tools for better dissemination in the use and management of scientific and technical health information. The studies by Morigi and Souto (2005), Kern (2020), Santos and Paiva (2020) and Santos (2020) were fundamental for this research, as they served as a theoretical basis for the development of this article.

Keywords: University libraries. Health science. Social media. Competence in information. COVID-19.

Submissão em: 21 abr. 2021

Aprovação em: 5 out. 2021

\section{INTRODUÇÃO}

A tecnologia está presente na vida de grande parte da população que possui acesso à Internet, e com isso, percebe-se no cotidiano, que a sociedade da informação utiliza cada vez mais as Tecnologias de Informação e Comunicação (TIC) para realizar diversas tarefas, seja para aprendizagem, entretenimento, ou uso profissional. Em virtude do isolamento social causado pela COVID-19,_o uso das TIC aumentou exponencialmente em 2020, com o consumo acelerado da Internet para fins de conferências de vídeo, redes sociais, aulas online, etc., exigindo-se do profissional bibliotecário maior competência em mídia.

Este artigo originou-se de uma dissertação apresentada ao Programa de PósGraduação em Biblioteconomia da Universidade Federal do Estado do Rio de Janeiro (UNIRIO), defendida em 08 de abril de 2020 com o tema "INFORMAÇÃO EM SAÚDE: proposta aplicada ao desenvolvimento da competência em informação com usuários de uma Biblioteca universitária", haja vista que o produto final dessa 
pesquisa serviu como base norteadora para dar inicio ao plano de trabalho via home office em uma biblioteca universitária especializada em ciências da saúde, especificamente nas áreas de Fisioterapia, Farmácia e Terapia ocupacional.

Em virtude do fechamento dos institutos federais, e consequentemente das bibliotecas frente à pandemia da COVID-19, foram pensadas ações com vistas a minimizar possíveis transtornos aos usuários da biblioteca, bem como garantir a continuidade dos serviços prestados mesmo durante a quarentena, decretada pelo governo em 22 de março de 2020. Essas ações foram colocadas em prática pela equipe de bibliotecárias em conjunto com os auxiliares, e propôs-se o projeto denominado "biblionaquarentena" a partir das ideias formuladas pela equipe, trabalhadas em torno de divulgações de conteúdos em mídias sociais sobre diversos assuntos. Uma das ideias implantadas, a que mais destacou-se entre os serviços inovadores, foi ter colocado em prática as recomendações para a construção de um Programa de Capacitação, produto desenvolvida pela bibliotecária do presente estudo, a qual serviu como fator crucial para alcançar os objetivos propostos nesta pesquisa, ou seja, como uma roteiro para implantar serviços inovadores mesmo durante a pandemia.

Diante do exposto, foi necessário abordar neste artigo uma breve descrição acerca das informações mais relevantes da dissertação como: o objetivo geral da pesquisa, a metodologia aplicada, alguns resultados da pesquisa e o estudo de caso realizado na biblioteca universitária, onde buscou descobrir se os usuários que a frequentam costumam realizar pesquisas de maneira eficiente, isto é, se possuem a competência em informação necessária para a busca da informação em saúde através das plataformas de pesquisas online.

Tal produção possui relação com o fazer bibliotecário no desenvolvimento da competência em informação dos alunos, docentes e técnicos administrativos do IFRJ, e também à comunidade externa, visto que as redes sociais, Facebook e Instagram, tornou-se a principal ferramenta de divulgação de serviços em tempos remotos, a qual atinge maior número de pessoas.

Esta pesquisa justifica-se por relatar a experiência de como a biblioteca colocou em prática as "recomendações para a construção de um Programa de Capacitação", divididas em 5 etapas: planejamento, implementação ou realização, divulgação, avaliação do curso e avaliação do Programa, as quais auxiliaram para o planejamento de cada ação. Dentre elas, propôs-se oferecer um curso de 
capacitação online, através da plataforma Google meet, com o intuito de auxiliar os alunos e professores do IFRJ e para a comunidade Externa no desenvolvimento da competência em informação na utilização das Normas da ABNT: NBR 6023 Referencias; NBR 14724 - Trab. Acadêmicos; NBR10520 - Citações; e NBR 6028 Resumos. Portanto, a pesquisa revela os resultados alcançados no percorrer dos 5 passos desenvolvidos como produto final do projeto de pesquisa.

Cabe destacar que o tema da capacitação ora apresentada foi escolhido pelos próprios alunos através de uma enquete elaborada no Instagram da biblioteca, a qual continha as seguintes opções: uso das principais bases de dados em saúde; como elaborar um artigo científico e capacitação sobre as normas da ABNT, logo, o curso que obteve-se mais votos foi o último. Dessa forma, a biblioteca pretende realizar posteriormente uma outra capacitação destinada às informações em saúde, no que tange em orientar os alunos na realização de pesquisas nas principais plataformas digitais, das quais oferecem uma expansão de informações em ciências da saúde, para fins de estudos e pesquisas científicas.

Desse modo, acredita-se que o estudo contribui como um modelo capaz de auxiliar outras bibliotecas universitárias, que almejam organizar alguma atividade cultural, evento ou curso, enquanto mediadoras de informação e promotoras do acesso à informação. Cabe destacar que diante da etapa 4, avaliação, elaborou-se um questionário para investigar se a capacitação ofertada pela biblioteca atendeu de fato as demandas dos usuários. Para isso, foi descrito ao longo do trabalho o passo a passo da avaliação, e os resultados alcançados mediante os dados coletados. A investigação Justifica-se também por revelar a atual realidade dos serviços prestados pela biblioteca, especialmente quanto à elaboração de conteúdos digitais em redes sociais, por meio da ferramenta Canva, desenvolvimento e apresentação de cursos à distância para o público interno e externo, o que é um grande desafio para o profissional da informação em termos de adaptação na continuidade dos serviços prestados pela biblioteca, revolucionando o papel do bibliotecário mediador em tempos de pandemia no desenvolvimento da competência em informação em meio digital.

Dessa forma, surge a pergunta, quais os desafios do profissional bibliotecário no auxílio do desenvolvimento da competência em informação ao público interno e externo de forma remota em tempos de pandemia? 
Diante do exposto, tem-se como objetivo geral refletir sobre as perspectivas, ações e novos desafios implantados pela Biblioteca universitária em estudo, em seu primeiro Programa de Capacitação que deu origem ao curso online "Aprendendo sobre normas da ABNT. Apresenta como objetivos específicos a) Analisar se a equipe, bibliotecária e auxiliar, possui a competência em mídia necessária para trabalhar de forma virtual; b) Identificar o olhar dos participantes quanto ao conteúdo e serviço oferecido no primeiro curso de capacitação online e c) Planejar ações futuras para a promoção de novos cursos ministrados a distância.

Quanto à metodologia aplicada, o estudo envolve uma análise empírica e descritiva, de abordagem qualiquantitativa, isto é, do tipo relato de experiência, que busca uma aproximação da teoria com a prática a respeito das recomendações propostas para a criação de um Programa de capacitação. Como instrumentos de coleta de dados, elaborou-se um questionário, desenvolvido na plataforma Google forms, totalizando sete questões com perguntas fechadas, em escala Likert e uma pergunta aberta, como forma de avaliar e coletar a opinião dos participantes quanto ao curso oferecido em dezembro de 2020. Realizou-se também a pesquisa bibliográfica, a fim de investigar na literatura conteúdos que abordam a respeito das atividades inovadoras implantadas pelas bibliotecas universitárias durante o período da quarentena.

\section{FUNDAMENTAÇÃO TEÓRICA}

A seguir, serão apresentadas importantes reflexões que giram em torno dos estudos teóricos sobre o aumento das tecnologias de Informação e Comunicação e bibliotecas universitárias em tempos da COVID-19, logo, os trabalhos de: Morigi e Souto (2005), Kern (2020), Santos e Paiva (2020) e Santos (2020) foram fundamentais para esta pesquisa, pois serviram como embasamento teórico para o desenvolvimento deste artigo.

\subsection{Bibliotecas universitárias em tempos da COVID-19}

Com o advento do novo coronavírus no mundo, a rotina e os hábitos das pessoas se transformaram radicalmente, nos lares, nas famílias, nos trabalhos, nos lazeres, etc. Dessa forma, busca-se alguma estratégia ou maneira de se reinventar, principalmente no mundo dos negócios, ou seja, de fazer com que o trabalho, independentemente da área, continue com suas atividades mesmo que seja de 
forma remota. O que não é diferente das bibliotecas, pois com o fechamento desses espaços, o profissional da informação passou a buscar novas medidas de como continuar com os serviços, agora, à distância, sem prejudicar os usuários que estão sempre em busca de informação e conhecimento.

Conforme Kern (2020, p. 1), “[...] o profissional bibliotecário se vê impossibilitado de atuar da maneira tradicional: é necessário reinventar, sobretudo no contexto universitário e no campo da atuação científica. Serviço de referência online, acervos virtuais, incentivo do uso de e-books [...]" e uma série de medidas emergenciais são implementadas.

[...] durante a pandemia a biblioteca universitária se adapta, aproximando-se dos usuários ao oferecer atendimentos, cursos, capacitações, divulgando eventos e opções culturais, ocupando espaço nas redes e mídias sociais, atualizando as bases de dados e repositórios institucionais, em modalidades virtuais à distância, atuando em teletrabalho (KERN, 2020, p.19).

Diante desse contexto, o profissional que atuava apenas de maneira tradicional, ou seja, ainda como mero localizador de fontes de informação, sem usufruir da TIC, apesar dessa ferramenta estar presente no ambiente da biblioteca, se viram diante de um verdadeiro caos. O profissional que já usufruía das redes sociais, mesmo que pouco utilizadas, para fins de informações básicas como divulgação de novos acervos, horários e informes dos produtos e serviços da biblioteca, também sofreram com novas demandas, serviços e ações a serem pensadas e disponibilizadas nas mídias sociais. Porém, o impacto foi menor, por já possuírem conhecimento no manuseio dessas ferramentas, especialmente nas habilidades de pesquisar também, em bases de dados para fins de recuperação da informação quando solicitada pelos usuários.

Essa nova realidade serviu para mostrar o quanto a TIC é fator crucial para a execução das tarefas, independentemente do cargo ou função, é através dela que hoje as atividades profissionais continuam suas funções, sendo possível o trabalho via home office. Por isso é preciso avançar e adquirir novos conhecimentos em função da evolução das tecnologias, pois nunca sabe-se o que o futuro reserva.

A introdução das tecnologias de informação e comunicação nas unidades de informação trouxe impactos nas bibliotecas e novas formas de sociabilidade entre os bibliotecários e os usuários. Elas são percebidas pelos bibliotecários como elementos facilitadores na execução das tarefas exigidas pela rotina do seu trabalho, além de auxiliarem os usuários no processo de busca das informações e do conhecimento, tornando-os mais autônomos (MORIGI; SOUTO, 2005, p. 203). 
É importante salientar que a TIC também traz desafios quanto às informações verdadeiras ou falsas, o que pode ocasionar sérios problemas de desinformação na sociedade. Esse momento contínuo de informações seguras ou não, mostra-se em

[...] decorrência da proatividade da comunicação da era digital que o momento exige, esse profissional bibliotecário tem que estar atento à disseminação de informações, usando ferramentas para aproximar o seu público e combatendo as informações falsas, as famosas fake news (SANTOS; PAIVA, 2020, p. 515).

Em termos do perfil do profissional da informação, muitos pensam que o bibliotecário é somente

[...] aquele profissional que realiza empréstimos e devoluções de livros que realiza buscas no sistema, a fim de recuperar uma informação quando solicitada pelo usuário no setor de referência, assim como a catalogação, indexação, classificação e armazenamento de livros nas estantes no processamento técnico [...] (SANTOS, 2020, p. 33).

Logo, acredita-se que com os novos serviços ofertados virtualmente, as pessoas passarão a ter outra visão do profissional, ou seja, como educador, pois como aponta Morigi e Souto (2005, p. 195), "[...] o bibliotecário deixou de ser um erudito, guardião dos livros para se tornar um profissional mediador no processo de busca da informação. Nesse sentido, ele pode ser visto como um educador do usuário." O ponto positivo que o trabalho remoto proporciona é enfatizar o bibliotecário

[...] em sua função educativa, visto que ele, além de possuir a competência em informação, deve exercer o papel de mediador, pois também é a sua responsabilidade fazer com que o aluno desenvolva a competência em informação naquilo que ele necessita [...] (SANTOS, 2020, p.33).

2.2 Resultado da pesquisa realizada no mestrado por Santos (2020): breve descrição da dissertação

Buscou-se em uma dissertação de Mestrado, analisar o caminho para o desenvolvimento da competência em informação com usuários de uma Biblioteca universitária, procurando responder a seguinte questão: Quais os comportamentos relacionados à busca e uso de informação, que podem ser otimizados pela implementação de um programa de capacitação para que ocorra a competência em informação? Como objetivo geral, o estudo buscou analisar o comportamento de busca e uso de informação dos usuários de uma biblioteca universitária especializada em ciências da saúde. 
Realizou-se um estudo empírico de natureza qualiquantitativa acerca desses usuários, a fim de identificar quais as suas dificuldades relação a busca e recuperação da informação das principais bases de dados em saúde. Para fins dessa investigação, elaborou-se um questionário com 26 questões como instrumento de coleta de dados destinado a um grupo de 12 alunos que concordaram em participar da pesquisa: 4 alunos de Fisioterapia, 4 de Terapia ocupacional e 4 de Farmácia. Os resultados da pesquisa foram ilustrados através de quadros comparativos, gráficos e respostas transcritas pelos alunos que participaram do questionário. Após analisar os dados, pode-se detectar as principais habilidades e/ou dificuldades quanto o manuseio das bases de dados: Lilacs, Scopus e Web of Science, Portal da Biblioteca Virtual em Saúde (BVS), Pubmed, e Capes, inclusive a falta de conhecimento tanto das ferramentas Medical Subject Headings (MeSH) e Descritores em Ciência da Saúde (DeCS), quanto as dificuldades do uso das regras impostas da norma Associação Brasileira de Normas Técnicas (ABNT). Dentre as perguntas, questionou-se: "Você concorda que a Biblioteca deve oferecer capacitações para o uso das bases de dados em saúde com mais frequência, como exemplo, um Programa de capacitação?" onde 100\% dos alunos responderam "sim".

Com bases nessa investigação e alcance dos resultados, foi imprescindível a elaboração de um roteiro para a construção de um Programa de Capacitação com a intenção de ditar os caminhos para a concretização desse Programa tão importante e almejado pelos alunos, sendo essencial para o desenvolvimento da competência em informação dos estudantes universitários com base nas ferramentas de busca na Internet voltadas para a saúde. As recomendações propostas por Santos (2020, p. 75), foram divididas em cinco etapas - Planejamento, Implementação ou Realização, Divulgação, Avaliação do curso e Avaliação do Programa:

1) Planejamento - A fim de melhor planejar a proposta do Programa de Capacitação, tais recomendações são essenciais para o desenvolvimento do curso:

a) Aprimorar os produtos e serviços de informação oferecidos pela Biblioteca;

b) Apoiar o professor da disciplina de metodologia científica nas atividades educacionais;

c) Valorizar, na comunidade acadêmica, o bibliotecário como educador; que, assim como o professor, também promove a atividade de ensinoaprendizagem;

d) Participar das reuniões do Colegiado de Campus, a fim de expor, à Direção e aos docentes coordenadores, a proposta do novo serviço da Biblioteca referente à capacitação das Bases de dados em saúde; 
e) Favorecer o desenvolvimento da competência em informação dos alunos ante as TIC - apresentando e ensinando a eles o manuseio das principais ferramentas de busca em saúde;

f) Definir se o Programa de Capacitação pode ser incluído como umas das atividades complementares ofertadas pelo Campus;

g) Planejar como se dará as inscrições para a participação da capacitação;

h) Definir o dia e a hora da capacitação de acordo com as demandas dos alunos inscritos;

i) Reservar com antecedência a sala do laboratório de informática para que aconteça a capacitação.

2) Implementação ou Realização - Com base no que os alunos responderam nas questões 8, 9 e 10, essas recomendações são voltadas para o auxílio e suporte das ferramentas que eles necessitam:

a) Apresentar e especificar os recursos tecnológicos que irão ser explorados durante o curso;

b) Apresentar e ensinar como manusear os Portais que abrangem as bases de dados em saúde, pois muitos alegaram dificuldades;

c) Oferecer suporte na análise de fontes confiáveis na área de saúde por meio do domínio das bases de dados, como Lilacs, Medline, Scopus e Web of Science;

d) Apresentar e ensinar o uso correto do descritor MeSH, o qual nunca é usado, conforme apresentado no levantamento da pesquisa;

e) Auxiliar quanto ao uso das normas de citação e de referências da ABNT, visto que alguns alunos também possuem certa dificuldade em como citar trabalhos, assim como organizar as referências;

f) Realizar uma breve revisão oral de todo conteúdo apresentado durante a capacitação.

3) Divulgação - A fim de definir como será a forma de divulgação do curso proposto: estabelecer, como estratégia de marketing, contato com os alunos via WhatsApp, e-mails e redes sociais como Facebook e Instagram, o dia e o período das inscrições para o Programa de Capacitação oferecido pela Biblioteca.

4) Avaliação - Com o intuito de definir uma proposta de avaliação do curso, ou seja, uma fase pós-capacitação: elaborar um breve questionário com perguntas fechadas e uma aberta, a fim de coletar a opinião dos alunos sobre a capacitação, e o que poderia ser melhorado ao final de cada curso;

5) Avaliação do Programa - Com o propósito de avaliar o Programa de Capacitação após a implementação: o Programa será avaliado para ajustes e elaboração de novas propostas.

Portanto, diante dos resultados da pesquisa, observa-se a importância da continuidade do fazer bibliotecário enquanto mediador e promotor da competência em informação frente às TICs em saúde, dentre outros conteúdos que agregam valor ao conhecimento durante a trajetória acadêmica, principalmente em tempos de pandemia, em que a tecnologia é fator crucial para prosseguir com a aprendizagem do aluno com êxito. Logo, a biblioteca universitária em estudo vem promovendo ações via remota com base também, nas dificuldades encontradas pelos alunos detectadas no resultado dessa pesquisa.

\section{METODOLOGIA}

A presente investigação caracteriza-se como um estudo empírico e descritivo, de abordagem qualiquantitativa, do tipo relato de experiência, que busca uma 
aproximação da teoria com a prática a respeito das recomendações propostas para a criação de um Programa de capacitação, em que buscou-se colocar na prática o curso "Aprendendo as normas ABNT" em caráter remoto.

A concretização desse Programa, ocorreu em etapas, sendo cada uma delas submetida à Coordenação de Extensão do Campus (CoEX), setor responsável pela promoção de cursos de extensão e oficinas para a comunidade, visando à formação, qualificação e treinamento profissional. O Curso teve seu conteúdo desenvolvido pela equipe, 50 vagas oferecidas e efetivamente 34 participantes, logo em seguida, sucedeu-se a avaliação. Utilizou-se um formulário desenvolvido na plataforma Doity para receber as inscrições e a divulgação ocorreu nas mídias sociais em novembro de 2020.

A investigação do caso proposto contou com uma avaliação da satisfação dos usuários quanto às expectativas dos participantes. Como instrumento de coleta de dados foi utilizado um questionário por sete perguntas fechadas, sendo a primeira questão optativa, e a questão de número 2 a 7 representando cinco categorias de resposta: 1) Ruim; 2) Regular; 3) Bom; 4) Ótimo; 5) Excelente aplicado em formato de escala Likert e composto também por uma pergunta aberta com o intuito de coletar a expressão escrita do aluno quanto ao curso e sua dinâmica bem como sugestões e/ou reclamações, entre outros aspectos.

As questões foram elaboradas e adaptadas a partir do modelo de um projeto piloto realizado pelo Serviço Nacional de Aprendizagem Comercial (Senac) (2014) intitulado "Documentação do Questionário de Avaliação - Projeto Piloto." A equipe optou por reaproveitar algumas questões utilizando perguntas breves e objetivas para que as respostas fossem diretas. O questionário foi enviado e disponibilizado por e-mail para os 34 participantes no dia 11 de dezembro de 2020. A equipe aguardou as respostas por uma semana, e dos 34 alunos convidados para responder a pesquisa, 16 aceitaram com êxito, o que permitiu a realização do presente estudo. Na seção seguinte serão descritos os resultados dessa pesquisa.

Para o desenvolvimento do trabalho, realizou-se também a pesquisa bibliográfica, a fim de investigar sobre o que está sendo analisado na literatura sobre o conteúdo temático. Para isso, foram recuperadas fontes como E-books, artigos, periódicos e pesquisa na Base de Dados Referenciais de Artigos de Periódicos em Ciência da Informação (Brapci), utilizando as seguintes palavras-chave: Bibliotecário 
mediador, Competência em informação, Pandemia, Biblioteca universitária, COVID19.

\section{ANÁLISE DOS RESULTADOS}

A seguir serão apresentados os resultados da investigação quanto a capacitação oferecida, de acordo a etapa 4 (avaliação) das recomendações, ou seja, o questionário denominado pesquisa de satisfação, que serviu como instrumento para coletar os dados das opiniões dos participantes do curso, que, conforme ilustrado na tabela 1 , dos 34 participantes, obteve-se 16 respondentes, o que permitiu a realização do presente estudo. Cabe ressaltar que os sujeitos envolvidos serão pormenorizados por meio da palavra "alunos" nas sete primeiras questões. E a partir da questão 8 serão descritos pela palavra "aluno" seguido de um numeral, por exemplo, "aluno 1", "aluno 2", “aluno 3" e assim por diante, como forma de representar as respostas dos 16 participantes da pesquisa de satisfação.

A questão 1 possui o propósito de descobrir por qual rede social ou fonte de informação, os alunos obtiveram conhecimento a respeito do curso de capacitação "Aprendendo as normas ABNT", desenvolvida com as seguintes opções: "Facebook", "Instagram", "Alguém me indicou" e "WhatApp." Conforme o gráfico 1, 25\% descobriram pela divulgação no Facebook, 43,8\% pelo Instagram, 25\% obtiveram conhecimento por indicação de alguém e 6,3\% ou seja, um aluno soube pelo WhatsApp, o que revela que a rede social Instagram está sendo o meio mais consultado no momento.

Gráfico 1 - Fonte de conhecimento do curso

Como você conheceu o curso?

16 respostas

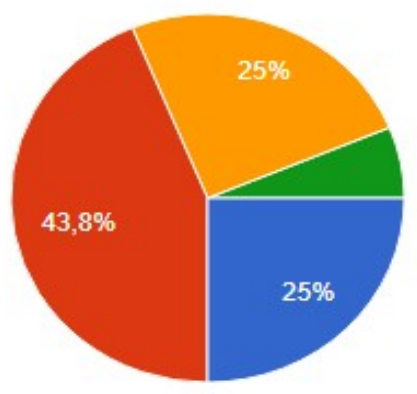

Facebook

Instagram

Alguém me indicou

Whats app

Fonte: Elaboração própria, 2021.

R. Bibliomar, São Luís, v. 20, n. 2, p. 224-239, jul./dez. 2021. 
Cabe ressaltar que as respostas da questão de número 2 a 7 estão ilustradas na tabela 1, representando cinco categorias de resposta: 1) Ruim, 2) Regular, 3) Bom, 4) Ótimo, 5) Excelente, aplicado em escala Likert.

A questão 2 buscou descobrir se o curso oferecido de forma online atendeu as expectativas dos alunos, e os dados mostram que $37,5 \%$ dos alunos marcaram "ótimo" e 62,5\% responderam "excelente", revelando que as expectativas esperadas foram alcançadas com êxito.

A questão 3 pretendeu analisar se a carga horária foi suficiente, e $25 \%$ responderam "bom", outros 25\% dos alunos disseram "ótimo" e 50\% marcaram "excelente" mostrando que o horário de 3 horas de curso foi suficiente para o aprendizado.

A questão 4 procurou investigar se o conteúdo foi adequado aos objetivos propostos, logo, 6,3\% respondeu "ótimo" e 93,8\% marcaram "excelente", dessa forma, mostra que o conteúdo estava de acordo com o estimado na divulgação do curso, mantendo o foco no objetivo proposto.

A questão 5 buscou descobrir se o instrutor demonstrou domínio e segurança nos conteúdos, e 31,3\% responderam "ótimo" e outros 68,8\% marcaram "excelente" o que mostra o quanto é importante o profissional possuir habilidades informacionais e transmitir o conteúdo de forma clara, didática e objetiva aos alunos.

A questão 6 procurou investigar se o instrutor foi organizado, onde 18,8\% disseram "ótimo" e 81,3\% responderam "excelente". Logo, a organização do material (conteúdo) também é essencial para manter o foco naquilo que irá ser apresentado, a fim de que a capacitação ocorra de maneira bem estruturada.

A questão 7 buscou descobrir com qual nota os alunos avaliariam o curso no todo, em que $25 \%$ dos alunos avaliaram o curso como "Bom", 18,8\% marcaram "ótimo e outros 56,3\% analisaram como excelente. Portanto, conclui-se que no geral, o curso foi satisfatório.

E por último, a questão 8 foi com base na afirmação "Use esse espaço para adicionar qualquer elogio, sugestão e/ou reclamação." Dos 16 participantes do questionário, apenas 8 responderam essa questão cujas respostas foram as seguintes:

Aluno 1 - Eu adorei o curso. Obrigada por proporcionar um curso com um tema muito importante.

Aluno 2 - Gostaria de agradecer! Fiquei super feliz com o aprendizado!

Aluno 3 - Muito bom. Espero que tenham outros. 
Aluno 4 - O curso foi muito enriquecedor, consegui tirar várias dúvidas.

Obrigada!

Aluno 5 - Parabéns pela proposta e pela exposição.

Aluno 6 - poderia ser dividido em duas partes pra enfocar mais conteúdos

Aluno 7 - Na minha opinião o curso poderia ter sido em 2 dias.

Aluno 8 - Adorei a ideia do curso!! Fiquei feliz em ter tido a oportunidade de participar!

Diante dessas opiniões, pode-se observar o quanto o curso foi enriquecedor para os aprendizados desses alunos, revelando o quanto o profissional deve investir nas atividades de educação/ mediação, ou seja, no desenvolvimento da competência em informação desses estudantes, independente do assunto que for abordar. Assim, apoia também o professor como um suporte a mais na aprendizagem.

Observou-se que dois alunos alegaram que o curso poderia ser dividido em dois dias. Apesar de ser a opinião da minoria, pode-se levar em consideração, pois a carga horária de 3 horas pode se tornar cansativa. Dessa forma, acredita-se que para os cursos futuros, a biblioteca pretende diminuir o tempo da capacitação para 2 horas ou dividir o conteúdo em dias diferentes.

A tabela 1 a seguir mostra os resultados da pesquisa de satisfação da questão de número 2 a 7 .

Tabela 1 - Questionário pesquisa de satisfação

\begin{tabular}{lccccc}
\hline Perguntas & Ruim & Regular & Bom & Ótimo & Excelente \\
\hline $\begin{array}{l}\text { 2) O curso online atendeu as suas } \\
\text { expectativas? }\end{array}$ & $0 \%$ & $0 \%$ & $0 \%$ & $37,5 \%$ & $62,5 \%$ \\
\hline 3) A carga horária foi suficiente? & $0 \%$ & $0 \%$ & $25 \%$ & $25 \%$ & $50 \%$ \\
\hline $\begin{array}{l}\text { 4) O conteúdo foi adequado aos } \\
\text { objetivos propostos? }\end{array}$ & $0 \%$ & $0 \%$ & $0 \%$ & $6,3 \%$ & $93,8 \%$ \\
$\begin{array}{l}\text { 5) O instrutor demonstrou domínio e } \\
\quad \text { segurança nos conteúdos? }\end{array}$ & $0 \%$ & $0 \%$ & $0 \%$ & $31,3 \%$ & $68,8 \%$ \\
6) O instrutor foi organizado? & $0 \%$ & $0 \%$ & $0 \%$ & $18,8 \%$ & $81,3 \%$ \\
7) Considerando o todo, com qual nota & $0 \%$ & $0 \%$ & $25 \%$ & $18,8 \%$ & $56,3 \%$ \\
$\quad$ você avalia o curso? & & & & & \\
\hline
\end{tabular}

Fonte: Elaboração própria, 2021

Acredita-se, portanto, que os resultados apresentados nesta pesquisa foram satisfatórios, revelando o quanto a capacitação, mesmo que a distancia, deve ser oferecida constantemente pela biblioteca, a fim de melhor contribuição no ensino- 
aprendizagem dos alunos como também inovar os produtos e serviços da biblioteca. Uma oportunidade para que os bibliotecários possam mostrar o seu outro lado profissional, ou seja, exercendo seu papel educativo diante das demandas dos usuários.

\section{CONSIDERAÇÕES FINAIS}

Este artigo teve como propósito refletir sobre as perspectivas, ações e novos desafios implantados em uma biblioteca universitária em seu primeiro Programa de Capacitação que deu origem ao curso online "Aprendendo sobre normas da ABNT". Diante dos resultados apresentados, pode-se dizer que as recomendações propostas no projeto de pesquisa escrito por Santos (2020) foram avaliadas como satisfatórias, permitindo a concretização do Programa. Quanto à execução do curso, no quesito virtual, apresentou-se de forma eficaz, permitindo a interatividade entre os alunos e a instrutora através da plataforma virtual Google Meet, logo, observouse que a grande maioria dos alunos possui a facilidade de acesso em suas próprias casas, havendo a possibilidade de propor outras capacitações de forma online.

Os resultados desta pesquisa contribuíram para atingir os objetivos específicos. Dessa forma, em consonância com o objetivo a): Analisar se a equipe, bibliotecárias e auxiliares, possuem a competência em mídia necessária para trabalhar de forma virtual, pode-se dizer que as ações executadas pela biblioteca continuam sendo benéficas para os usuários, pois a equipe está sempre planejando formas de aproximar os alunos através de dicas quanto ao uso de ferramentas digitais, sobre a ABNT, informes em geral, e divulgações dos serviços inovadores prestados pela biblioteca, tudo isso pelas redes sociais Facebook e Instagram.

Cabe ressaltar que o uso da ferramenta Canva, o aplicativo gratuito para realização das artes, foi um desafio para o profissional, em termos de uso, pois é através dessa ferramenta que são criados os diversos posters para divulgações nas redes sociais, o que possibilita a criação de uma melhor identidade visual da biblioteca. Portanto, conclui-se que a equipe possui a competência midiática para proporcionar a interatividade entre a biblioteca e os usuários através das mídias sociais.

Quanto ao objetivo b): Identificar o olhar dos participantes quanto ao conteúdo e serviço oferecido no primeiro curso de capacitação online, observou-se que dentre os 16 participantes do questionário, a capacitação foi avaliada de forma satisfatória, 
inclusive, diante das respostas, almejam por mais capacitações como esta, o que revela a necessidade de aprimorar cada vez mais suas habilidades informacionais. Logo, diante da análise dessa pesquisa, revela-se o quanto é importante a função do bibliotecário enquanto educador e mediador para o desenvolvimento da competência em informação desses estudantes e também a comunidade externa, que, com o uso das redes tem alcançado um público maior nas atividades oferecidas pela biblioteca.

E por último, o objetivo c): Planejar ações futuras para a promoção de novos cursos ministrados a distância, neste sentido, a biblioteca continua planejando ações com o intuito de ofertar novos cursos com diferentes conteúdos temáticos, principalmente os voltados para o uso de ferramentas das bases de dados em saúde, já que muitos ainda possuem certas dificuldades no momento da pesquisa, segundo o estudo levantado por Santos (2020), para uma melhor disseminação no uso e gestão da informação científico-técnica em saúde.

Dessa forma, em tempos tão desafiadores na saúde mundial, a biblioteca continuará unindo esforços para melhor servir aos alunos em termos educacionais, ou seja, continuar com a assistência e auxílio aos usuários, a fim de levar informação, inovação e conhecimento em saúde de modo constante, tanto para a comunidade interna, quanto para a externa.

\section{REFERÊNCIAS}

KERN, Lucas Martins. A biblioteca universitária e a pandemia do novo coronavirus: reflexões e prospectivas. Revista Informação \& Universidade, Rio Grande do Sul, v. 2, n. esp. p. 1-21, jul./dez. 2020. Disponível em:

http://reviu.febab.org.br/index.php/reviu/article/view/30/36. Acesso em: 13 jan. 2021.

MORIGI, V. J.; SOUTO, L. R. Entre o passado e o presente: as visões de biblioteca no mundo contemporâneo. Revista ACB: biblioteconomia em Santa Catarina, Florianópolis, v. 10, n. 2, p. 189-206, jan./dez. 2005. Disponível em:

https://revista.acbsc.org.br/racb/article/view/432/552. Acesso em: 07 mar. 2021.

SANTOS, Cássia Rosania Nogueira dos; PAIVA, Cintia Luciano de. Ações de atuação dos bibliotecários do IFRJ em meio à pandemia da covid-19. In: DANIELA Spudeit; CLAUDIA Souza (org.). Atuação dos profissionais da Arquivologia, Biblioteconomia e Museologia em época de pandemia. Florianópolis, SC: Nyota: Rocha Gráfica, 2020. p. 515 - 530. E-book. Disponível em: https://3b2d7e5d-8b9a4847-aa3e-40931d588fb7.filesusr.com/ugd/c3c80a_14b6b7a184014cfa87b8fe37a6a da1af.pdf. Acesso em: 11 jan. 2021

SANTOS, Karina Barbosa dos. Informação em saúde: proposta aplicada ao desenvolvimento da competência em informação com usuários de uma Biblioteca universitária. 2020. 94f. Dissertação (Mestrado em Biblioteconomia) - Programa de 
Pós-Graduação em Biblioteconomia, Universidade Federal do Estado do Rio de Janeiro, Rio de Janeiro, 2020.

SERVIÇO Nacional de Aprendizagem Comercial. Documentação do Questionário de Avaliação - Projeto Piloto. Rio de Janeiro: SENAC, 2014. Disponível em:

http://sistemas.to.senac.br/sei/docs/Avaliacao_Piloto.pdf. Acesso em: 19 jan. 2021. 